\title{
Endoscopic Examinations in Children with Recurrent Abdominal Pain
}

\author{
by \\ PITONO SOEPARTO \\ (From the Department of Child Health, Airlangga School of Medicine \\ Dr. Soetomo Hospital, Surabaya)
}

\begin{abstract}
Much difficulties are often encountered in finding the underlying cause of recurrent abdominal pain. Clinical features may vary from one patient to the other and occasionally from one episode to the next even in the same child. The recent development of fibre optic endoscopy may well prove to have a useful diagnostic technique, particularly in those children in whom other investigations are inconclusive.

The result of endoscopic examinations in children with recurrent abdominal pain comprising of 62 children aged between 3-13 years were as follows : erosion in 7 children, oesophagitis in 4 children, duodenitis in 3 children, spasm of the pylorus in 2 children, and normal findings were found in 30 children. Of the 30 patients with "normal" endoscopic findings, 7 had psychosomatic problems, 4 had allergy, 4 had urinary tract infection, 2 showed giardiasis, one had epilepsy, 1 was treated as pulmonary tuberculosis, where as in 11 patients organic as well as nonorganic abnormalities could not be found. There seem to be of no significant correlation between the endocopic and upper gastrointestinal series findings. Endoscopy seem to be of a safe and reliable tool in the diagnosis of a number of organic intestinal lesions otherwise not detected by ordinary investigations.
\end{abstract}


A child is said to have the syndrome of recurrent abdominal pain if at least three attacks of pain, severe enough to affect activity, have recurred during a period of 3 months or longer (Apley, 1975; Roy et al., 1975). The syndrome of recurrent abdominal pain may result from a number of conditions or as a manifestation of functional gastrointestinal illness with a varied and erratic history.

In the course of the nineteenth century it had become an almost unchallenged axiom that the study of disease should be approached from two completely different points of view : the organic approach or the psychological attitude. But modern psychosomatics has demonstrated that this distinction is not always in harmony with the observed facts : emotional processes can produce and influence organic illness, organic disturbances can produce mental disease. However, the differentiation between primarily organic and nonorganic disorder remains one of the basic trends of medical practice (Apley, 1975). Every

physician should therefore make a careful and unbiased exploration of possible organic causes of recurrent abdominal pain as well as a search for areas which may be recognized as emotionally stressful.

Much difficulties are however often encountered in finding the underlying cause of recurrent abdominal pain. Clinical features may vary from one patient to the other and occasionally from one episode to the next even in the same child. Like other medical problems, recurrent abdominal pain in children has many underlying factors influencing each other, and in a large number of investigations attention has been focused on one to the virtual exclusion of the remainder.

The recent development of fibre optic endoscopy may well prove to have a useful diagnostic technique, particularly in those children in whom other investigations are inconclusive. The purpose of this study is to evaluate the results of endoscopic examinations carried out in children presenting with recurrent abdominal pain.

\section{Materials and methods}

A total of 62 children aged between 3-13 years presenting the symptom of recurrent abdominal pain (RAP) underwent endoscopical examinations. They had complained of at least three episodes of abdominal pain during a period of 3 month or longer.

Routine studies included: complete blood examinations, stool examinations for ova and parasites, urine analysis, urine cultur, blood urea nitrogen and serum creatinine, serum transaminases, serum amylase, chest and plain abdominal rontgenograms. Up- per gastrointestinal (UGI) series, electroencephalograms, intravenous pyelograms, ultrasonography were occasionally performed.

The diagnosis of food allergy was based on food elimination and challenge studies. The diagnosis of psychosomatic disturbances was established by the identification of definite psychologic or emotional abnormalities and confirmed by a psychiatrist. Family history in the form of interview was taken to provide solid information pertaining to the origin of the pain.
Results

Females predominated males in presen- in a ratio of $2: 1$. They were evenly disting symptoms of recurrent abdominal pain tributed among the age groups (Table 1).

rable 1: Age and sex distribution

\begin{tabular}{|l|c|c|c|c|}
\hline & $3-5$ years & $6-8$ years & $9-13$ years & Total \\
\hline Female & 14 & 14 & 12 & 40 \\
Male & 6 & 11 & 5 & 22 \\
\hline Total & 20 & 25 & 17 & 62 \\
\hline
\end{tabular}

Most patients experienced recurrent ab- time of onset of symptom was uncertain dominal pain less than one year, there re- (Table 2)

mains 21 patients of whom the precise

Table 2 : Duration of illness

\begin{tabular}{lcccccc}
\hline Duration of illness & $3-5 \mathrm{mo}$ & $6-8 \mathrm{mo}$ & $9-12 \mathrm{mo}$ & $2 \mathrm{yr}$ & $3 \mathrm{yr}$ & $?$ \\
\hline No. of patients & 10 & 14 & 13 & 3 & 1 & 21 \\
\hline
\end{tabular}

Table 3 : Endoscopic findings

\begin{tabular}{lcccc} 
& \multicolumn{3}{c}{ Age group (Year) } & Total \\
\cline { 2 - 5 } & $3-5$ & $6-8$ & $9-13$ & \\
\hline Endoscopic findings : & 2 & 2 & - & 4 \\
Esophagitis & 3 & 1 & 3 & 7 \\
Gastritis & 1 & 1 & 1 & 3 \\
Duodenitis & 1 & 4 & 2 & 7 \\
Erosion & 1 & 2 & 2 & 5 \\
Ulcer & 2 & - & 2 & 4 \\
Polyp & - & 2 & - & 2 \\
Pyloric spasm & 10 & 13 & 7 & 30 \\
Normal & 20 & 25 & 17 & 62 \\
\hline Total & & & & \\
\hline
\end{tabular}


It shows in Table 3 that among 62 en- If the patients were grouped into funcdoscopic examinations, esophagitis was tional disturbances (pyloric spasm, normal found in 4 patients $(6.4 \%)$, gastritis in 7 endoscopic finding) and organic lesions $(11.29 \%)$, duodenitis in $3(4.83 \%)$, erosion (esophagitis, gastritis, duodenitis, erosion, in $7(11.29 \%)$, ulcer in $5(8.07 \%)$, polyp in ulcer, polyp), the following will be obtain$4(6.45 \%)$, spasm of pylorus in $2(3.23 \%)$ ed (Table 4$)$ : and normal finding in $30(48.39 \%)$.

Table 4 : Functional and organic lesions

\begin{tabular}{|l|cccc|}
\hline & \multicolumn{4}{|c|}{ Age group (Year) } \\
\cline { 2 - 5 } & $3-5$ & $6-8$ & $9-12$ & Total \\
\hline Functional & 10 & 15 & 7 & 32 \\
Organic lession & 10 & 10 & 10 & 30 \\
\hline Total & 20 & 25 & 17 & 62 \\
\hline
\end{tabular}

Organic lesions constituted nearly half of to be no significant correlation between the endoscopic findings of patients with the result of UGI series and endoscopic recurrent abdominal pain. There appeared findings.

Table 5 : Endoscopic findings related to UGI series

\section{Endoscopic finding}

Ulcer

Erosion

Polyp

Duodenitis

Gastritis

Esophagitis

Pyloric spasm

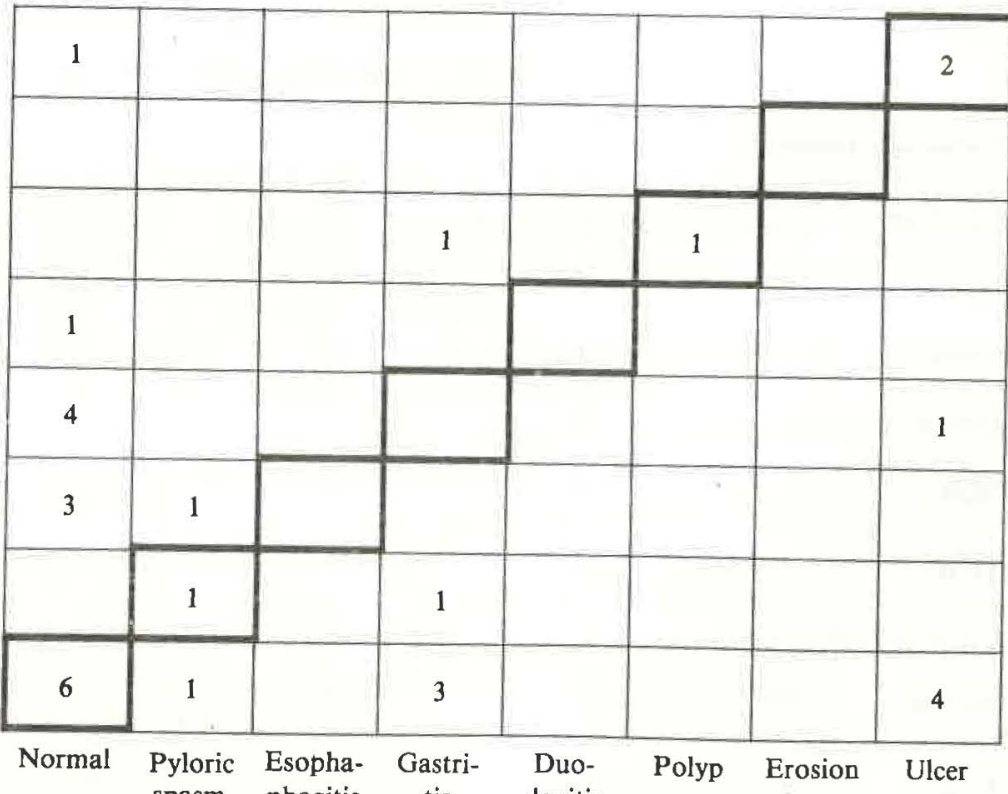

spasm phagitis tis denitis

Radiological appearance

Intestinal lesions were found in $41.64 \%$ endoscopical findings, 11 remained without of patients with psychosomatic difficulties (Table 6). Of 30 patients with normal any evidence of associated diseases (Table 7)

Table 6 : Endoscopic findings of patients with psychosomatic disturbances $(N=12)$

\begin{tabular}{lccccc} 
& Normal & Gastritis & Duodenitis & Erosion & Ulcer \\
\hline $\begin{array}{l}\text { No of } \\
\text { patients }\end{array}$ & $\begin{array}{c}7 \\
(58.33 \%)\end{array}$ & 1 & 1 & 2 & 1
\end{tabular}

$(41.64 \%)$

Table 7 : Disease states of patients showing no abnormalities on endoscopy

\begin{tabular}{lccccccc} 
& Psychosomatic & Allergy & UTI & Giardia & Epilepsi & TB & $(-)$ \\
\hline $\begin{array}{l}\text { No of } \\
\text { patients }\end{array}$ & 7 & 4 & 4 & 2 & 1 & 1 & 11 \\
\hline
\end{tabular}

UTI : Urinary tract infection

TB : Tuberculosis

\section{Discussion}

A study of recurrent abdominal pain comprising 48 Indonesian children has previously been done by Soeparto et al. in 1981 which was based mainly on diagnostic UGI series. Of 48 patients studied, only 13 $(27.08 \%)$ showed intestinal lesions on Xray. Compared to $48.39 \%$ of the present study, conventional barium radiological studies of the upper gastrointestinal tract may of less diagnostic value compared to endoscopical examination, since intestinal mucosal lesions are frequently shallow (Marrone and Silca, 1984; Bendig, 1983). There seem also of no significant correlation between UGI series and endoscopical results. The limitations of barium contrast studies versus endoscopy have also been demonstrated in several studies (Bendig, 1983). Fibre optic endoscopy helps not only to establish with greater certainty than before the presence or abscence of ulcers in dyspeptic patients, but it has also facilitated such diagnosis as "'gastritis" and 'duodenitis" (Lagarde and Spiro, 1984).

The syndrome of recurrent abdominal pain may result from a number of conditions which are mostly difficult to determine. A compelling model proposed by Barr divides children with recurrent $a b-$ dominal pain into three groups : "organic", "dysfunctional" and " psychogenic" (cited from Levine 1984). The ex- 
act cause of the syndrome in the present had endoscopic and/or histological eviseries remains incompletely understood dence of acute gastroduodenitis but no visialthough intestinal lesions were visible in ble ulcer crater. This raise the question nearly half of the cases endoscopically.

The concept that psychogenic factors are triggering events in the production of the pain is generally accepted. However, it is not clear as to whether this respons reflects a genetic or an acquired susceptibility, or both in the child. Though the gastrointestinal tract seems to be the target organ receiving the brunt of emotional input, a generalized disturbance of the autonomic system may exist (Roy et al., 1975). The importance of psychogenic elements in the genesis of the syndrome was also put forward by several authors (Girdany, 1953; Chapman et al., 1956; Lam, 1984). It is further suggested that emotional distress could be the primary and through $\mathrm{C} \mathrm{N} \mathrm{S}$ stimulus as the end pathway may markedly affect gastric motility, hypersecretion and finally to "gastritis" and duodenitis" (Lagarde and Spiro, 1984). The present study showed that of 12 patients presumed to have psychogenic disturbance, 5 $(41.64 \%)$ have intestinal lesions on endoscopy.

There remain however 11 patients $(17.74 \%)$ of whom neither endoscopic abnormalities nor associated diseases could be detected. The possible underlying causes need to be further elucidated.

Gastritis and duodenitis are often diagnosed empirically and without adequate substantiation. The diagnosis should be reserved for inflammation of the gastric or duodenal mucosa and should be made only by endoscopy or mucosal biopsy. There is some controversy over whether gastritis and duodenitis are indeed responsible for dyspeptic symptoms. In a study Creenlaw et al. in 1981 (cited from Lagarde and Spiro, 1984) found that 41 percent of patients with classic symptoms of duodenal ulcer disease
Regarding the erosion the answer is not histologically evident erosion in the gastroduodenal mucosa represent a step in the continuation from normal to fullblown peptic ulcer disease. Abdominal discomfort the gastroduodenal mucosa (Lagarde and may or may not related to the erosion of
Spiro, 1984).

Polyps of the gastrointestinal tract may cause recurrent episodes of abdominal pain (Dickson, 1977; Arey, 1975). Juvenile polyps are common tumors of the gastrointestinal tract in early life. The polyps are usually located in the rectum, less frequently in the sigmoid colon and uncommonly in the more proximal colon, the small intestine or the stomach. They are usually solitary.

The other disease causing recurrent abdominal pain is esophagitis. It may be associated with hypersecretion with or without evidence of hiatal hernia or poo gastroesophageal sphincter control (Levine and Rappaport, 1984). Signs that are pecu-

liar to children with esophagitis, especially those of the immediate preschool and early school age are personality disorders. Esophagitis may also a symptom in children who experience incompetence of the gastroesophageal sphincter.

Although endoscopy become a more sensitive and specific modality than standard $\mathrm{X}$-ray techniques, there remain many causes possibly playing a role in recurrent abdominal pain which are beyond the reach of endoscopy. Such underlying causes can sometimes only be detected by rontgenogram. Endoscopy is therefore no meant to be a first-line diagnostic procedure but rather to complement X-ray studies. Apart of diagnostic value, endoscopy may also be regarded as a psychological approach to convince both the parents and child that no real organic disease is in fact present.

\section{REFERENCES}

1. APLEY, J : The Child with Abdominal Pains; 2nd. ed. pp. 92 (Blackwell Scientific Publications, Oxford 1975).

2. AREY, J.B.: Neoplasms and neoplastic like lesions; in Vaughan, Mc Kay, Nelson, Textbook of Pediatrics, 10th, ed. pp 1612 (Saunders/lgaku Shoin, Tokyo 1975).

3. Bendig, D.W. Peptic Disease; in Kelly, Practice of Pediatrics, Vol 5, pp 1-2 (Harper \& Row Philadelphia 1983).

4. CHAPMAN, A.H.; LOEB, D.G.; YOUNG, Y.B.: A psychosomatic study of five children with duodenal ulcer. J. Pediat. $48: 246$ (1956)

5. CHRISTIE, D.L.; AMENT, M.E.: Gastric acid hypersecretion in children with duodenal ulcer. Gastroenterology 71: 242-244 (1976).

6. DICKSON, J.A.S.: Surgical conditions in the in fant and older child; in Harries, Essentials of

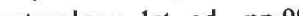
Paediatric Gastroenterology, 1st. ed., pp 98-99 (Churchill Livingstone, Edinburg 1977).

7. GIRDANY, B.R.: Peptic ulcer in childhood. Pediatrics 12: 56-61 (1953).
8. GOLDBERG, H.M.: Duodenal ulcers in children. Br. med. J. i : 1500-1502 (1957)

9. LAGARDE, S.P.; SPIRO, H.M.: Non ulcer dyspepsia. Clin. Gastroenterol. 13: 437-446 (1984).

10. LAM, S.K.: Pathogenesis and pathophysiology of duodenal ulcer. Clin. Gastroenterol. 13: 447 471 (1984)

11. LEVINE, M.D.; RAPPAPORT, L.A.: Recurrent abdominal pain in school children: The reliness of the long distance physician. Pediat. Clins N. Am. 31: 969-991 (1984).

12. MARRONE, G.C.; SILEN, W.: Pathogenesis, diagnosis and treatment of acute gastric mucosal lesions. Clin. Gastroenterol. 13: 635-650 (1984).

13. ROY, C.C.; SILVERMAN, A; COZZETTO F.J.: Pediatric Clinical Gastroenterology, 2nd ed., pp. 342-349 (Mosby, St. Louis 1975).

14. SOEPARTO, P.; DJUPRI, L; RUSTIADJI, SANDIH: Recurrent abdominal pain in children. Paediatr. Indones. 21: 168-174 (1981). 